\title{
Relation between proinflammatory mediators and epithelial-mesenchymal transition in head and neck squamous cell carcinoma
}

\author{
GEUN-WOO DONG ${ }^{1}$, NAM-YONG DO ${ }^{1}$ and SUNG-CHUL LIM ${ }^{2,3}$ \\ Departments of ${ }^{1}$ Otorhinolaryngology, and ${ }^{2}$ Pathology; ${ }^{3}$ Research Center for Resistant Cells, \\ Chosun University School of Medicine, Gwangju, Korea
}

Received July 5, 2010; Accepted July 20, 2010

DOI: $10.3892 /$ etm.2010.124

\begin{abstract}
Increasing evidence suggests that the tumor microenvironment plays an important role in tumor progression and oncogenesis. Various proinflammatory mediators contribute to tumor proliferation, neoangiogenesis, invasion, metastasis, and resistance to cancer therapy such as hormonal therapy and chemotherapy. The major causes of death related to head and neck squamous cell carcinoma (HNSCC) include cervical node and distant metastases. Epithelial-mesenchymal transition (EMT) has been identified to play a key role in mediating the tumor invasion and metastasis of carcinomas. Herein, the relationship between proinflammatory mediators and EMT in HNSCC was investigated. Immunohistochemical expression of interleukin-1 $\beta$ (IL-1 $\beta$ ), cyclooxygenase-2 (COX-2), Slug and E-cadherin in relationship to histologic differentiation, clinical stage and nodal status was evaluated in 146 surgical specimens of HNSCC. A correlation was noted between increased expression of IL- $1 \beta$ and nodal status, as well as increased expression of COX-2 and histologic differentiation, clinical stage and nodal status. Increased Slug expression was correlated with histologic differentiation and clinical stage. Decreased E-cadherin expression was correlated with histologic differentiation and nodal status. A significant relationship was observed between IL-1 $\beta$ and COX-2. However, a significant inverse correlation was noted between Slug and E-cadherin. A significant relationship was observed between increased proinflammatory mediator IL-1 $/ \mathrm{COX}-2$ expression and increased EMT marker Slug/E-cadherin expression. These results indicate that proinflammatory mediators IL-1 $\beta$ and COX-2 may induce EMT through an increase in Slug and a decrease in E-cadherin. The present findings suggest that various anti-inflammatory agents could be used as an adjuvant
\end{abstract}

Correspondence to: Dr Sung-Chul Lim, Department of Pathology, Chosun University Hospital, 588 Seosuk-dong, Dong-gu, Gwangju 501-717, Korea

E-mail: sclim@chosun.ac.kr

Key words: interleukin-1 $\beta$, cyclooxygenase-2, Slug, E-cadherin, epithelial-mesenchymal transition, head, neck, squamous cell carcinoma treatment modality with anti-cancer chemotherapeutic drugs in HNSCC.

\section{Introduction}

Through invasion and metastasis, head and neck squamous cell carcinoma (HNSCC) becomes fatal. If an involvement of the inflammatory process in the mechanisms of metastasis is confirmed, then potential novel targets for cancer treatment may be identified (1). However, the mechanisms involved in the invasive growth of tumors and the induction of metastasis are not yet completely known. Since most cancer-related deaths are caused by metastasis, this field has been the focus of study in the past several years. According to previously reported theories, the processes involved in the invasive growth and metastasis of tumors are complex and vary depending not only on the intrinsic characteristics of the tumor cells themselves, but also on the microenvironments where tumors originate. In particular, inflammation occurring in the vicinity of tumors contributes to tumor cells acquiring invasive and metastatic potential by cytokines, chemokines and growth factors released by the infiltrated inflammatory cells $(2,3)$. Interleukin- $1 \beta$ (IL-1 $\beta$ ) is involved in tumor progression, treatment resistance $(4,5)$ and increased expression of cyclooxygenase-2 (COX-2) in HNSCC (6-8). COX-2 is an inducible enzyme involved in the initiation of inflammation and mitogenic response. In addition to its action on the regulation of inflammation and cell growth, COX-2 is associated with carcinogenesis and tumorigenesis (9-11). Several prostaglandins (PGs), particularly $\mathrm{PGE}_{2}$, play the role of accelerator in the process of tumorigenesis by stimulating angiogenesis and suppressing immune surveilance (9). COX-2 is regulated by IL-1 $\beta$, lipopolysaccharide, tumor necrosis factor- $\alpha$ and reactive oxygen species (ROS) (12).

Epithelial-mesenchymal transition (EMT), the process of cells losing the characteristics of epithelial cells and acquiring the characteristics of mesenchymal cells, has been implicated in the process of tumor progression in carcinoma cases. EMT has been reported to be closely associated with the invasion and metastasis of tumors and is associated with a poor patient prognosis $(13,14)$. As EMT-inducing factors, Slug, Twist, SIP1, Zeb1 and E47 induce EMT by suppressing 
Table I. Clinical, epidemiologic and histologic characteristics of 146 patients with head and neck squamous cell carcinoma.

\begin{tabular}{lc}
\hline Characteristic & No. $(\%)$ \\
\hline No. of patients & $146(100)$ \\
Age (years) & \\
Mean & 61.6 \\
Range & $26-87$ \\
Gender & \\
Male & $130(89.0)$ \\
Female & $16(11.0)$ \\
Tumor stage & \\
Early (I, II) & $91(62.3)$ \\
I & 37 \\
II & 54 \\
Advanced (III, IV) & $55(37.7)$ \\
III & 16 \\
IV & 39 \\
Tumor site & \\
Oral cavity & $37(25.3)$ \\
Pharynx & $48(32.9)$ \\
Larynx & $61(41.8)$ \\
Degree of tumor differentiation & \\
Well differentiated & $83(56.9)$ \\
Moderately differentiated & $53(36.3)$ \\
Poorly differentiated & $10(6.9)$ \\
Lymph node metastasis & \\
Yes & $58(39.7)$ \\
No & $88(60.3)$ \\
\hline
\end{tabular}

the expression of E-cadherin and subsequently inducing the invasion and metastasis of tumors (15). Slug is a member of the Snail family. It plays an important role in the regulation of EMT by suppressing various epithelial markers. E-cadherin is a cell adhesion molecule located in the cell adhesion site of epithelial cells; it plays an important role in the suppression of tumor invasion. When E-cadherin is decreased or inactivated, the malignant potential of tumors is increased and metastasis is induced (16).

In the present study, we investigated whether inflammatory mediators are involved in EMT by comparing and examining the significance of the expression of the proinflammatory mediators IL- $1 \beta$ and COX-2, and Slug and E-cadherin, determined by immunohistochemical techniques applied to HNSCC tissues. Furthermore, the relationship between the expression pattern of Slug and E-cadherin and the expression pattern of the proinflammatory mediators IL- $1 \beta$ and COX-2 was examined. The aim of the study was to identify novel approaches to cancer treatment.

\section{Materials and methods}

Patients. The study consisted of 146 consecutive patients with HNSCC who underwent surgical treatment for primary tumors at the Department of Otorhinolaryngology, Chosun University, from 1994 to 2002. The clinical, epidemiologic and histopathologic characteristics of the patients are listed in Table I. None of the patients had previously received preoperative chemotherapy or radiotherapy. Fifty-eight of the 146 patients (39.7\%) had histologically confirmed cervical lymph node metastasis, whereas the remaining 88 patients $(60.3 \%)$ had no clinical or histopathologic evidence of neck disease. Tumors were staged according to the AJCC TNM classification (17) and graded as follows: well, moderately and poorly differentiated.

Immunohistochemistry. Upon approval of the Institutional Review Board, immunohistochemistry was carried out on formalin-fixed, paraffin-embedded HNSCC tissues from the Pathology Department archives. All tumors investigated in the study were tested for rabbit polyclonal IL-1 $\beta$ (dilution 1:200) (Santa Cruz Biotechnology Inc., Santa Cruz, CA, USA), mouse monoclonal COX-2 (dilution 1:300) (Cayman Chemical, Ann Arbor, MI, USA), goat polyclonal Slug (dilution 1:100) (Santa Cruz Biotechnology Inc.) and mouse monoclonal E-cadherin (dilution 1:100) (Santa Cruz Biotechnology Inc.). Immunolocalization for IL-1 $\beta$ was performed using a Polink-2 HRP Plus rabbit DAB detection system (Golden Bridge International, Inc., WA, USA). Immunolocalization for COX-2 and E-cadherin was performed using an HRP Plus mouse DAB detection system (Golden Bridge International, Inc.), and immunolocalization for Slug was performed using an HRP Plus goat DAB detection system (Golden Bridge International, Inc.) according to the supplier's protocol (LSAB kit; Dako, Carpinteria, CA, USA). Counterstaining was performed with Mayer's hematoxylin. An isotype-matched control antibody was also used. Inflammed granulation tissue was used as the positive control for IL-1 $\beta$ and COX-2. The positive control for Slug was colonic adenocarcinoma with strong nuclear staining in a previous study, and the positive control for E-cadherin was a normal colonic mucosa adjacent tumor. Instead of the primary antibody, TBS was used for the negative control.

Analysis and interpretation of staining. A pathologist, blinded to the clinical course of the subjects in order to exclude subjectivity, evaluated the staining results. Staining for IL-1 $\beta$ and COX-2 was determined as positive when intracytoplasmic staining was identified under an optical microscope in $>5 \%$ of the tumor cells in each tissue section. Positive expression of IL-1 $\beta$ was divided into categories: weakly positive when $5-20 \%$ of tumor cells were stained and strongly positive when $>20 \%$ of tumor cells were stained. Positive expression of COX-2 was divided into categories: weakly positive when $5-50 \%$ of tumor cells were stained and strongly positive when $>50 \%$ of tumor cells were stained (18). For the evaluation of Slug expression, staining intensity was scored as 0 (negative), 1 (weak), 2 (medium) and 3 (strong). Extent of staining was scored as $0(0 \%), 1$ (1-25\%), 2 (26-50\%), 3 (51-75\%) and 4 (76-100\%), according to the percentage of the positively stained areas in relation to the entire cancerous area. The sum of the intensity and extent of staining score was used as the final staining score (0-7) for Slug. Tumors having a final staining score of $\geq 6$ were considered to exhibit high 


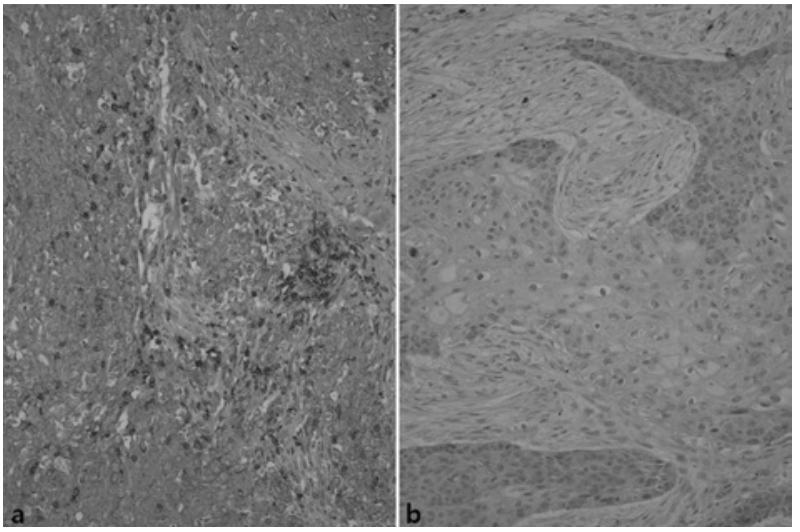

Figure 1. Immunohistochemical staining of laryngeal squamous cell carcinoma for IL-1 $\beta$. (a) Poorly differentiated squamous cell carcinoma showed strong positive cytoplasmic staining. Some tumor infiltrating lymphocytes also showed a positive reaction. (b) Well-differentiated squamous cell carcinoma showed weakly positive cytoplasmic staining in tumor cells. Polink-2 HRP Plus rabbit DAB detection system and counterstaining by hematoxylin was carried out.

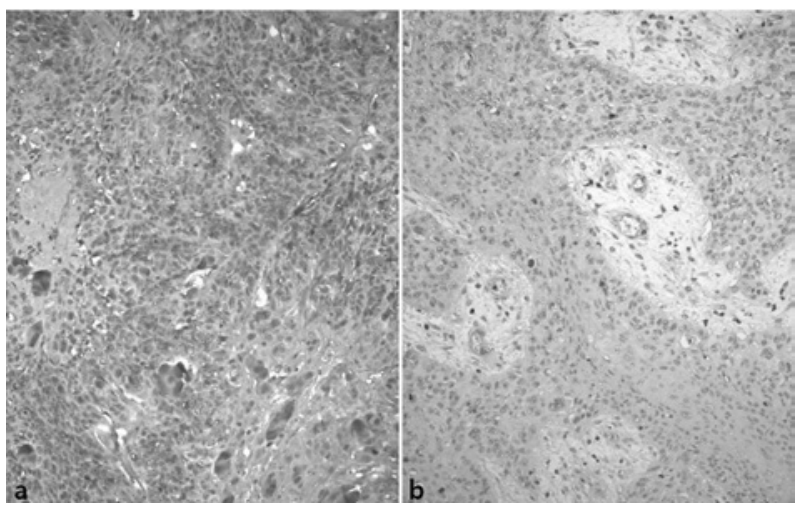

Figure 2. Immunohistochemical staining of laryngeal squamous cell carcinoma for COX-2. (a) Poorly differentiated squamous cell carcinoma showed strong positive cytoplasmic staining in the majority of tumor cells and some tumor infiltrating lymphocytes or macrophages. (b) Well-differentiated squamous cell carcinoma showed weakly positive cytoplasmic staining in some tumor cells and tumor infiltrating lymphocytes or macrophages. Polink-2 HRP Plus mouse DAB detection system and counterstaining by hematoxylin was carried out.

expression (19). For the evaluation of E-cadherin, staining intensity was scored as 0 (negative), 1 (weak), 2 (medium) and 3 (strong). The extent of membranous E-cadherin expression in tumor cells was scored as $0(<5 \%), 1(5-25 \%), 2(26-50 \%), 3$ $(51-75 \%)$ and $4(76-100 \%)$. The sum of the intensity and extent of staining score was used as the final staining score (0-7) for E-cadherin. Tumors having a final staining score of $\geq 6$ were considered to exhibit high expression (19).

Statistical analysis. The StatView software package (Abacus Conceptus, Berkeley, CA, USA) was used for statistical analysis. The Chi-square test was used to determine the correlation between clinical stage, histologic tumor grade and lymph node metastasis and the expression patterns of IL- $1 \beta$, COX-2, Slug and E-cadherin. Correlations in the expression patterns between IL-1 $\beta$ and COX-2; Slug and E-cadherin;

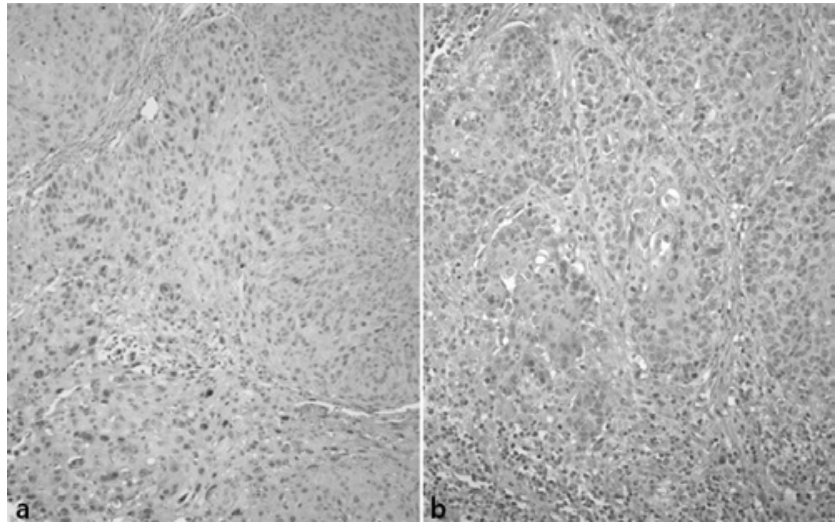

Figure 3. Immunohistochemical staining of laryngeal squamous cell carcinoma for Slug. (a) Poorly differentiated squamous cell carcinoma showed high nuclear expression of Slug in the majority of tumor cells. (b) Welldifferentiated squamous cell carcinoma showed low nuclear expression of Slug in some tumor cells. Polink-2 HRP Plus goat DAB detection system and counterstaining by hematoxylin was carried out.

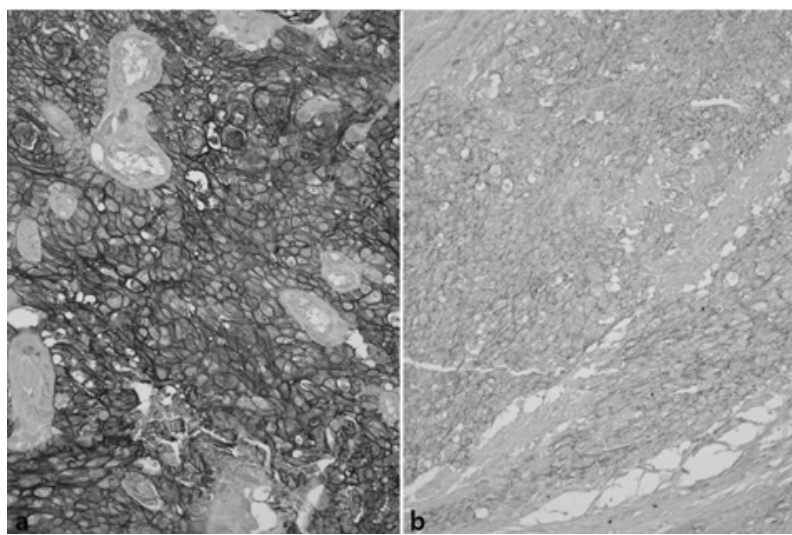

Figure 4. Immunohistochemical staining of laryngeal squamous cell carcinoma for E-cadherin. (a) Well-differentiated squamous cell carcinoma showed high membranous expression of E-cadherin in the majority of tumor cells. (b) Poorly differentiated squamous cell carcinoma showed low membranous expression of E-cadherin in the majority of tumor cells. Polink-2 HRP Plus mouse DAB detection system and counterstaining by hematoxylin was carried out.

IL-1//COX-2 and Slug/E-cadherin were identified. Statistical significance was determined at $\mathrm{p}<0.05$.

\section{Results}

$I L-1 \beta, C O X-2$, Slug and E-cadherin expression according to immunohistochemistry. IL-1 $\beta$ staining was positive in some lymphocytes and macrophages infiltrating the vicinity of tumors, while in some adjacent fibroblasts or tumor cells weak immunoreactivity was observed. Among the study subjects, 54 patients $(37 \%)$ exhibited a strong reaction to $\mathrm{IL}-1 \beta, 76$ cases $(52 \%)$ demonstrated a weak positive reaction and 16 cases (11\%) showed a negative reaction (Fig. 1).

A weak positive reaction for COX-2 was noted in the mucosal epithelia in the vicinity of the tumors. Macrophages, vascular endothelial cells and fibroblasts showed a weak positive cytoplasmic reaction. Regarding COX-2, 96 cases $(66 \%)$ 
Table II. Clinicopathologic data according to the expression pattern of IL-1 $\beta$ and COX-2 in head and neck squamous cell carcinoma.

\begin{tabular}{|c|c|c|c|c|c|c|}
\hline & \multicolumn{3}{|c|}{ IL- $1 \beta^{\mathrm{a}}$} & \multicolumn{3}{|c|}{$\mathrm{COX}-2^{\mathrm{b}}$} \\
\hline & $\begin{array}{l}\text { Strong } \\
(\mathrm{n}=54)\end{array}$ & $\begin{array}{c}\text { Weak } \\
(n=76)\end{array}$ & $\begin{array}{l}\text { Absent } \\
(\mathrm{n}=16)\end{array}$ & $\begin{array}{l}\text { Strong } \\
(\mathrm{n}=96)\end{array}$ & $\begin{array}{c}\text { Weak } \\
(\mathrm{n}=43)\end{array}$ & $\begin{array}{c}\text { Absent } \\
(\mathrm{n}=7)\end{array}$ \\
\hline \multicolumn{7}{|l|}{ Differentiation } \\
\hline W/D (n=83) & 29 & 45 & 9 & 49 & 31 & 3 \\
\hline $\mathrm{M} / \mathrm{D}(\mathrm{n}=53)$ & 21 & 26 & 6 & 40 & 10 & 3 \\
\hline $\mathrm{P} / \mathrm{D}(\mathrm{n}=10)$ & 4 & 5 & 1 & 7 & 2 & 1 \\
\hline \multicolumn{7}{|l|}{ Stage } \\
\hline Early (n=91) & 26 & 56 & 9 & 54 & 31 & 6 \\
\hline Advanced ( $\mathrm{n}=55)$ & 28 & 20 & 7 & 42 & 12 & 1 \\
\hline \multicolumn{7}{|l|}{ Nodal status } \\
\hline Negative $(n=88)$ & 28 & 46 & 14 & 53 & 29 & 6 \\
\hline Positive $(\mathrm{n}=58)$ & 26 & 30 & 2 & 43 & 14 & 1 \\
\hline
\end{tabular}

Table III. Clinicopathologic data according to the expression pattern of Slug and E-cadherin in head and neck squamous cell carcinoma.

\begin{tabular}{|c|c|c|c|c|}
\hline & \multicolumn{2}{|c|}{ Slug } & \multicolumn{2}{|c|}{ E-cadherina,c } \\
\hline & $\begin{array}{c}\text { Low } \\
(n=67)\end{array}$ & $\begin{array}{l}\text { High } \\
(\mathrm{n}=79)\end{array}$ & $\begin{array}{c}\text { Low } \\
(\mathrm{n}=91)\end{array}$ & $\begin{array}{c}\text { High } \\
(\mathrm{n}=55)\end{array}$ \\
\hline \multicolumn{5}{|l|}{ Differentiation } \\
\hline W/D (n=83) & 49 & 34 & 44 & 39 \\
\hline $\mathrm{M} / \mathrm{D}(\mathrm{n}=53)$ & 15 & 38 & 39 & 14 \\
\hline $\mathrm{P} / \mathrm{D}(\mathrm{n}=10)$ & 3 & 7 & 8 & 2 \\
\hline \multicolumn{5}{|l|}{ Stage } \\
\hline Early (n=91) & 50 & 41 & 59 & 32 \\
\hline Advanced $(\mathrm{n}=55)$ & 17 & 38 & 32 & 23 \\
\hline \multicolumn{5}{|l|}{ Nodal status } \\
\hline Negative $(\mathrm{n}=88)$ & 41 & 47 & 51 & 37 \\
\hline Positive $(\mathrm{n}=58)$ & 26 & 32 & 40 & 18 \\
\hline
\end{tabular}

W/D, well differentiated; M/D, moderately differentiated; P/D, poorly differentiated; Early, stages I and II; Advanced, stages III and

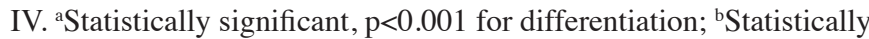
significant, $\mathrm{p}<0.05$ for stage; ${ }^{\mathrm{S} S t a t i s t i c a l l y ~ s i g n i f i c a n t, ~} \mathrm{p}<0.05$ for nodal status.

of the study subjects showed a strong positive reaction, 43 cases (29\%) showed a weak positive reaction and 7 cases (5\%) showed a negative reaction (Fig. 2).

Slug was stained in the nucleus of the tumor cells. Of the total cases, 79 (54\%) showed high expression and 67 (46\%) demonstrated low expression (Fig. 3).
E-cadherin was diversely stained on the cell membrane of the tumor cells. The entire cell membranes of epithelial cells forming the normal mucosa in the vicinity of tumors demonstrated strong and distinct staining. Concerning E-cadherin, 55 cases showed high expression (38\%) and 91 cases $(62 \%)$ showed low expression (Fig. 4) (Tables II and III).

Relationship between IL-1 $\beta$ expression and clinicopathologic parameters. The expression pattern of IL- $1 \beta$ was significantly correlated with the presence or absence of lymph node metastasis. As the expression of IL- $1 \beta$ inceased, the rate of lymph node metastasis was also significantly increased $(\mathrm{p}<0.05)$. Nevertheless, the expression of IL-1 $\beta$ was not significantly correlated with tumor differentiation and clinical stage (Table II).

Relationship between COX-2 expression and clinicopathologic parameters. A significant correlation between histological differentiation, clinical stage and the presence or absence of lymph node metastasis and the expression level of COX-2 was noted ( $\mathrm{p}<0.05$ each). In other words, as the differentiation grade of squamous cell carcinoma became poorer and the clinical stage increased, the strong positive expression of COX-2 was significantly increased, including in the group with lymph node metastasis (Table II).

Relationship between Slug expression and clinicopathologic parameters. A significant correlation was noted between histological differentiation and clinical stage of the tumors and the expression of Slug ( $<<0.001$ and $<0.05$, respectively). As the differentiation of the squamous cell carcinoma became poorer and as the clinical stage increased, the strong positive expression of COX-2 was significantly increased. However, a significant correlation between Slug and the presence or absence of lymph node metastasis was not noted (Table III). 
Table IV. Correlation between the expression of IL-1 $\beta$ and COX-2 in head and neck squamous cell carcinoma.

\begin{tabular}{lcccc}
\hline & \multicolumn{3}{c}{ COX-2 } & p-value \\
\cline { 2 - 4 } & $\begin{array}{c}\text { Strong } \\
(\mathrm{n}=96)\end{array}$ & $\begin{array}{c}\text { Weak } \\
(\mathrm{n}=43)\end{array}$ & $\begin{array}{c}\text { Absent } \\
(\mathrm{n}=7)\end{array}$ & \\
\hline IL-1 $\beta$ & & & & $<0.05$ \\
Strong $(\mathrm{n}=54)$ & 45 & 9 & 0 & \\
Weak $(\mathrm{n}=76)$ & 51 & 24 & 1 & \\
Absent $(\mathrm{n}=16)$ & 0 & 10 & 6 & \\
\hline
\end{tabular}

IL-1 $\beta$, interleukin-1 $\beta$; COX-2, cyclooxygenase-2.

Table V. Correlation between the expression of Slug and E-cadherin in head and neck squamous cell carcinoma.

\begin{tabular}{lccc}
\hline & \multicolumn{2}{c}{ E-cadherin } & p-value \\
\cline { 2 - 3 } & Low $(\mathrm{n}=91)$ & $\operatorname{High}(\mathrm{n}=55)$ & \\
\hline Slug & & & $<0.005$ \\
Low (n=67) & 29 & 38 & \\
High (n=79) & 62 & 17 & \\
\hline
\end{tabular}

Relationship between E-cadherin expression and clinicopathologic parameters. The histological differentiation and lymph node status significantly correlated with the expression level of E-cadherin $(\mathrm{p}<0.001$ and $<0.05$, respectively). As the histological differentiation became poorer, or in the group with lymph node metastasis, the expression of E-cadherin was significantly reduced. Nonetheless, E-cadherin expression was not significantly correlated with clinical stage (Table III).

Relationship between $I L-1 \beta$ and COX-2 expression. The expression of IL-1 $\beta$ and COX-2 showed a significant correlation $(\mathrm{p}<0.05)$. In the cases strongly expressing IL-1 $\beta$, COX-2 also showed the tendency to be strongly expressed. In the cases weakly expressing IL-1 $\beta$, COX-2 also showed the tendency to be weakly expressed (Table IV).

Relationship between Slug and E-cadherin expression. The expression of Slug and E-cadherin showed a significantly inverse correlation $(\mathrm{p}<0.005)$. In the cases strongly expressing Slug, E-cadherin showed the tendency to be weakly expressed. In the cases weakly expressing Slug, E-cadherin showed the tendency to be strongly expressed (Table V).

Relationship between IL-1 $/ \mathrm{COX}-2$ and Slug/E-cadherin expression. IL-1 $\beta$ was positively correlated with Slug, yet statistical significance was not achieved. However, IL-1 $\beta$ was inversely correlated with E-cadherin, with statistical significance $(\mathrm{p}<0.05)$. COX-2 was positively correlated with Slug, and statistical significance was achieved $(\mathrm{p}<0.05)$. COX-2 was
Table VI. Correlation between the expression of IL-1 $\beta / C O X-2$ and Slug/E-cadherin in head and neck squamous cell carcinoma.

\begin{tabular}{lccccc}
\hline & \multicolumn{2}{c}{ Slug $^{\mathrm{a}}$} & & \multicolumn{2}{c}{ E-cadherin ${ }^{\mathrm{b}}$} \\
\cline { 2 - 3 } \cline { 5 - 6 } & $\begin{array}{c}\text { Low } \\
(\mathrm{n}=67)\end{array}$ & $\begin{array}{c}\text { High } \\
(\mathrm{n}=79)\end{array}$ & & $\begin{array}{c}\text { Low } \\
(\mathrm{n}=91)\end{array}$ & $\begin{array}{c}\text { High } \\
(\mathrm{n}=55)\end{array}$ \\
\hline IL-1 & & & & \\
Strong $(\mathrm{n}=54)$ & 17 & 37 & & 46 & 8 \\
Weak $(\mathrm{n}=76)$ & 40 & 36 & & 41 & 35 \\
Absent $(\mathrm{n}=16)$ & 10 & 6 & & 4 & 12 \\
COX-2 & & & & \\
Strong $(\mathrm{n}=96)$ & 28 & 68 & & 63 & 33 \\
Weak $(\mathrm{n}=43)$ & 34 & 9 & & 26 & 17 \\
Absent $(\mathrm{n}=7)$ & 6 & 1 & 2 & 5 \\
\hline
\end{tabular}

IL-1 $\beta$, interleukin-1 $\beta ;$ COX-2, cyclooxygenase- 2 . ' Statistically significant, $\mathrm{p}<0.05$ in the comparison of Slug and COX -2 ; ${ }^{\text {bStatistically }}$ significant, $\mathrm{p}<0.05$ in the comparison of E-cadherin and IL- $1 \beta$.

inversely correlated with E-cadherin, but statistical significance was not achieved (Table VI).

\section{Discussion}

EMT is a prerequisite mechanism in developmental stages, and is a process whereby cells lose polarity and acquire a mesenchymal phenotype. EMT has been shown to play a central role in the induction of invasion and metastasis involved in the progression of tumors (14,20-23). The major cause of death in HNSCC is lymph node and distant metastases, such as lung metastases $(24,25)$. According to studies, a decrease or loss of E-cadherin is generally associated with aggressiveness in tumors, which results in poor tumor differentiation, anaplasia and invasive growth (26-29). The reduction in E-cadherin induced by the binding of Snail to the E-box of the E-cadherin promoter results in the suppression of E-cadherin transcription, which induces EMT $(30,31)$. When the suppression of E-cadherin was induced by Snail, tumors were found to acquire invasive characteristics and to readily form metastases (30). In addition, Snail was found to induce the expression of matrix metalloproteinase-2 (MMP-2) and to suppress cell-cell adhesion, contributing to an increase in tumor invasiveness (32). This was confirmed by a previous study. When the expression of Snail was suppressed by the use of siRNA, the EMT phenotype disappeared, MMP-2 activity was reduced, the migration and invasiveness of cells were reduced in vitro and metastatic potential was elevated in vivo (33).

In the present study, when the EMT level was evaluated by the reduction in E-cadherin, an inverse correlation between the reduction in E-cadherin and the differentiation of tumors and lymph node metastasis was observed. This confirmed that EMT plays an crucial role in the invasion, metastasis and the differentiation of tumors.

Slug, a member of the Snail family, is a molecule that plays an important role in embryonic development (34). Slug 
is a Snail transcription factor and is involved in the progression and metastasis of various types of tumors (35-37). Thus, Slug plays a role in enhancing the aggressiveness of tumors by suppressing E-cadherin through Snail.

In the present study, the expression of Slug was positively correlated with the differentiation of tumors, and clinical stage and was inversely correlated with E-cadherin. These findings corroborate previous theories.

In HNSCC, the elevation of Snail expression is associated with activation by Akt or other mechanisms. However, only approximately $30 \%$ of cases of metastasis are associated with Snail. In some of the remaining patients, NBS1 was reported to be involved. Cancer occurs preferentially in the Nijmegen breakage syndrome (NBS), the chromosomal-instability syndrome associated with radiosensitivity and growth retardation. The NBS gene product is NBS1 (38).

Inflammation is a finding frequently associated with invasive tumors (3). In HNSCC, an increase in the levels of various inflammatory mediators has been observed (39). COX-2 is an inducible enzyme that is elevated or decreased depending on the condition and activity (9). COX-2 is regulated by various cytokines and ROS. It is involved in inflammatory reactions and is in charge of the regulatory action of cell growth by the involvement in the mitotic reaction. COX-2 is also involved in the tumorigenic and carcinogenic process (9-12). The COX-2dependent up-regulation of Snail leads to a reduction in E-cadherin and contributes to EMT. IL- $1 \beta$ has been reported to be associated with the invasion, metastatic potential and treatment resistance of HNSCC, and to elevate the expression of COX-2 $(13,14)$. Therefore, the expression of IL-1 $\beta$ and COX-2 may be closely related.

In the present study, the expression of IL- $1 \beta$ was positively correlated with lymph node metastasis, and COX-2 was positively correlated with not only histological differentiation, but also with clinical stage and lymph node metastasis. In addition, the expression of IL-1 $\beta$ was positively correlated with the expression of COX-2. Therefore, an increase in IL-1 $\beta$ expression is anticipated to increase the expression of COX-2, leading to a reduction in E-cadherin through the up-regulation of COX-2-dependent Snail, which may induce EMT. This was substantiated by the results of our study.

Ultimately, the elevation of proinflammatory mediators may induce EMT, and thus may augment the aggressiveness of tumors. In contrast, when proinflammatory mediators are blocked due to the suppression of the Snail axis, the EMT may disappear, resulting in the suppression of the invasiveness or metastatic potential of tumors.

The results of our study not only provide useful information regarding the diagnosis of HNSCC and the prediction of prognosis, but also present crucial data for the development of effective treatments to block the invasion and metastasis of cancer.

Numerous studies have been conducted to characterize the association of inflammation with the development of cancer $(40,41)$ and also with inflammation within tumors. Studies have demonstrated that inflammation induced by tumor necrosis associated with chemotherapy may mediate effects on the progression and metastasis of tumors. The theory of the role of anti-inflammatory agents was proposed, not only for cancer treatment, but also for its prevention (42).
The result of our study revealed that inflammation may mediate the effects on the progression and metastasis of cancer and, specifically, that it may act by the induction of the EMT process.

The aggressiveness of cancer, such as invasiveness and metastatic potential, is controlled by a multitude of factors. Among these, proinflammatory mediators have been suggested to play a role. Thus, it is timely to consider the administration of anti-inflammatory agents concurrently with anti-cancer chemotherapeutics, in other words, the effect of COX-2 blockers according to the theory elucidated previously (43). COX-2 blockers also inhibit the release of $\mathrm{PGE}_{2}$, and subsequently block $\mathrm{PGE}_{2}$-mediated E-cadherin transcription suppressors and suppress EMT. Hence, a reduction in the metastatic potential of HNSCC is anticipated.

Collectively, these results further support the possibility that COX-2 blockers may play an important role in the effective treatment of HNSCC. In addition, not only COX-2 blockers, but also various other types of anti-inflammatory agents may be effective. Additional in vitro and in vivo studies are required to verify the link between IL-1ß/COX-2 and Slug/E-cadherin expression.

\section{Acknowledgements}

This study was supported by a grant from the National Research Foundation of Korea (NRF) funded by the Ministry of Education, Science and Technology (MEST) through the Research Center for Resistant Cells (R13-2003-009).

\section{References}

1. Zender CA and Petruzzelli GJ: Why do patients with head and neck squamous cell carcinoma experience distant metastases: can they be prevented? Curr Opin Otolaryngol Head Neck Surg 2: 101-104, 2005.

2. Lin DT, Subbaramaiah K, Shah JP, Dannenberg AJ and Boyle JO: Cyclooxygenase-2: a novel molecular target for the prevention and treatment of head and neck cancer. Head Neck 8: 792-799, 2002.

3. Wu Y and Zhou BP: Inflammation: a driving force speeds cancer metastasis. Cell Cycle 15: 3267-3273, 2009.

4. Mukhopadhyay P, Ali MA, Nandi A, Carreon P, Choy H and Saha D: The cyclin-dependent kinase 2 inhibitor down-regulates interleukin- $1 \beta$-mediated induction of cyclooxygenase-2 expression in human lung carcinoma cells. Cancer Res 66: 1758-1766, 2006.

5. Teruel A, Romero M, Cacalano NA, Head C and Jewett A: Potential contribution of naive immune effectors to oral tumor resistance: role in synergistic induction of VEGF, IL-6, and IL-8 secretion. Cancer Immunol Immunother 57: 359-366, 2008.

6. Bancroft CC, Chen Z, Yeh J, Sunwoo JB, Yeh NT, Jackson S, Jackson $\mathrm{C}$ and van Waes C: Effects of pharmacologic antagonists of epidermal growth factor receptor, PI3K and MEK signal kinases on NF- $\kappa \mathrm{B}$ and AP-1 activation and IL-8 and VEGF expression in human head and neck squamous cell carcinoma lines. Int J Cancer 99: 538-548, 2002.

7. Wolf JS, Chen Z, Dong G, Sunwoo JB, Bancroft CC, Capo DE, Yeh NT, Mukaida N and van Waes C: IL (interleukin)-1 $\alpha$ promotes nuclear factor- $\kappa \mathrm{B}$ and AP-1-induced IL-8 expression, cell survival, and proliferation in head and neck squamous cell carcinomas. Clin Cancer Res 7: 1812-1820, 2001.

8. Tsai CC, Chen CC, Lin CC, Chen CH, Lin TS and Shieh TY: Interleukin-1 $\beta$ in oral submucous fibrosis, verrucous hyperplasia and squamous cell carcinoma tissues. Kaohsiung J Med Sci 15: 513-519, 1999.

9. Williams CS, Mann M and DuBois RN: The role of cyclooxygenases in inflammation, cancer, and development. Oncogene 18: 7908-7916, 1999. 
10. Langenbach R, Loftin CD, Lee $\mathrm{C}$ and Tiano $\mathrm{H}$ : Cyclooxygenasedeficient mice. A summary of their characteristics and susceptibilities to inflammation and carcinogenesis. Ann NY Acad Sci 889: 52-61, 1999.

11. Callejas NA, Casado M, Diaz-Guerra MJM, Bosca L and Martin-Sanz P: Expression of cyclooxygenase-2 promotes the release of matrix metalloproteinase-2 and -9 in fetal rat hepatocytes. Hepatology 33: 860-867, 2001.

12. Martin-Sanz P, Callejas NA, Casado M, Diaz-Guerra MJ and Bosca L: Expression of cyclooxygenase-2 in foetal rat hepatocytes stimulated with lipopolysaccharide and pro-inflammatory cytokines. Br J Pharmacol 125: 1313-1319, 1998.

13. Thiery JP: Epithelial-mesenchymal transitions in tumour progression. Nat Rev Cancer 2: 442-454, 2002.

14. Thiery JP and Sleeman JP: Complex networks orchestrate epithelial-mesenchymal transitions. Nat Rev Mol Cell Biol 7: 131-142, 2006.

15. Peinado H, Olmeda D and Cano A: Snail, Zeb and bHLH factors in tumour progression: an alliance against the epithelial phenotype? Nat Rev Cancer 7: 415-428, 2007.

16. Shioiri M, Shida T, Koda K, Oda K, Seike K, Nishimura M, Takano $\mathrm{S}$ and Miyazaki M: Slug expression is an independent prognostic parameter for poor survival in colorectal carcinoma patients. Br J Cancer 19: 1816-1822, 2006.

17. Beahrs OH, Henson DE, Hutter RVP and Kennedy BJ (eds) Manual for Staging for Cancer. 4th edition. American Joint Committee on Cancer. JB Lippincott, Philadelphia, 1992.

18. Lim SC, Park SY and Do NY: Correlation of cyclooxygenase-2 pathway and VEGF expression in head and neck squamous cell carcinoma. Oncol Rep 10: 1073-1079, 2003.

19. Kyo S, Sakaguchi J, Ohno S, Mizumoto Y, Maida Y, Hashimoto M, Nakamura M, Takakura M, Nakajima M, Masutomi $\mathrm{K}$ and Inoue M: High Twist expression is involved in infiltrative endometrial cancer and affects patient survival. Hum Pathol 37: 431-438, 2006.

20. Barbera MJ, Puig I, Domínguez D, Julien-Grille S, Guaita-Esteruelas S, Peiró S, Baulida J, Francí C, Dedhar S, Larue L and García de Herreros A: Regulation of Snail transcription during epithelial to mesenchymal transition of tumor cells. Oncogene 23: 7345-7354, 2004

21. Zhou BP, Deng J, Xia W, Xu J, Li YM and Gunduz M: Dual regulation of Snail by GSK-3beta-mediated phosphorylation in control of epithelial-mesenchymal transition. Nat Cell Biol 6 : 931-940, 2004

22. Larue L and Bellacosa A: Epithelial-mesenchymal transition in development and cancer: role of phosphatidylinositol 3 kinase/ AKT pathways. Oncogene 24: 7443-7454, 2005.

23. Thompson EW, Newgreen DF and Tarin D: Carcinoma invasion and metastasis: a role for epithelial-esenchymal transition? Cancer Res 65: 5991-5995, 2005.

24. Leemans CR, Tiwari R, Nauta JJ, van der Waal I and Snow GB: Regional lymph node involvement and its significance in the development of distant metastases in head and neck carcinoma. Cancer 71: 452-456, 1993.

25. Ferlito A, Rinaldo A, Buckley JG and Mondin V: General considerations on distant metastases from head and neck cancer. ORL J Otorhinolaryngol Relat Spec 63: 189-191, 2001.

26. Brabant G, Hoang-Vu C and Cetin Y: E-cadherin: a differentiation marker in thyroid malignancies. Cancer Res 53: 4987-4993, 1993.

27. Naito A, Iwase H, Kuzushima T, Nakamura T and Kobayashi S: Clinical significance of E-cadherin expression in thyroid neoplasms. J Surg Oncol 76: 176-180, 2001.
28. Rocha AS, Soares P, Fonseca E, Cameselle-Teijeiro J, Oliveira MC and Sobrinho-Simoes M: E-cadherin loss rather than $\beta$-catenin alterations is a common feature of poorly differentiated thyroid carcinomas. Histopathology 42: 580-587, 2003.

29. Kato N, Tsuchiya T, Tamura G and Motoyama T: E-cadherin expression in follicular carcinoma of the thyroid. Pathol Int 52: 13-18, 2002.

30. Batlle E, Sancho E, Franci C, Dominguez D, Monfar M and Baulida J: The transcription factor snail is a repressor of E-cadherin gene expression in epithelial tumour cells. Nat Cell Biol 2: 84-89, 2000

31. Cano A, Pérez-Moreno MA, Rodrigo I, Locascio A, Blanco MJ, del Barrio MG, Portillo F and Nieto MA: The transcription factor snail controls epithelial-mesenchymal transitions by repressing E-cadherin expression. Nat Cell Biol 2: 76-83, 2000.

32. Yokoyama K, Kamata N, Fujimoto R, Tsutsumi S, Tomonari M and Taki M: Increased invasion and matrix metalloproteinase-2 expression by Snail-induced mesenchymal transition in squamous cell carcinomas. Int J Oncol 22: 891-898, 2003.

33. Yang MH, Chang SY, Chiou SH, Liu CJ, Chi CW, Chen PM, Teng SC and Wu KJ: Overexpression of NBS1 induces epithelial-mesenchymal transition and co-expression of NBS1 and Snail predicts metastasis of head and neck cancer. Oncogene 26: 1459-1467, 2007.

34. Nieto MA, Sargent MG, Wilkinson DG and Cooke J: Control of cell behavior during vertebrate development by Slug, a zinc finger gene. Science 6: 835-859, 1994.

35. Hajra KM, Chen DY and Fearon ER: The SLUG zinc-finger protein represses E-cadherin in breast cancer. Cancer Res 15: 1613-1618, 2002.

36. Martin TA, Goyal A, Watkins G and Jiang WG: Expression of the transcription factors snail, slug, and twist and their clinical significance in human breast cancer. Ann Surg Oncol 12: 488-489, 2005.

37. Uchikado $Y$, Natsugoe $S$, Okumura $H$, Setoyama $T$, Matsumoto M, Ishigami S and Aikou T: Slug expression in the E-cadherin preserved tumors is related to prognosis in patients with esophageal squamous cell carcinoma. Clin Cancer Res 11: 1174-1180, 2005

38. D'Amours D and Jackson SP: The Mre11 complex: at the crossroads of DNA repair and checkpoint signalling. Nature Rev Mol Cell Biol 3: 317-327, 2002

39. Loercher A, Lee TL and Ricker JL: Nuclear factor-кB is an important modulator of the altered gene expression profile and malignant phenotype in squamous cell carcinoma. Cancer Res 64: 6511-6523, 2004.

40. Chiba T and Marusawa $\mathrm{H}$ : A novel mechanism for inflammationassociated carcinogenesis; an important role of activation-induced cytidine deaminase (AID) in mutation induction. J Mol Med 87: 1023-1027, 2009.

41. Costa AC, Figueiredo $\mathrm{C}$ and Touati E: Pathogenesis of Helicobacter pylori infection. Helicobacter 14 (Suppl 1): 15-20, 2009.

42. Lim SC, Kim SM, Choi JE, Kim CH, Duong HQ, Han SI and Kang HS: Sodium salicylate switches glucose depletion-induced necrosis to autophagy and inhibits high mobility group box protein 1 release in A549 lung adenocarcinoma cells. Oncol Rep 19: 1165-1171, 2008.

43. Boolbol SK, Dannenberg AJ, Chadburn A, Martucci C, Guo XJ, Ramonetti JT, Abreu-Goris M, Newmark HL, Lipkin ML, DeCosse JJ and Bertagnolli MM: Cyclooxygenase-2 overexpression and tumor formation are blocked by sulindac in a murine model of familial adenomatous polyposis. Cancer Res 56: 2556-2560, 1996. 